\title{
pH-Responsive and Buffering Macromolecule Aqueous Absorbent and Mathematic Model-Based Feasibility Evaluation for $\mathrm{SO}_{2}$ Capture
}

\author{
Wei Feng ${ }^{1} \cdot{\text { Wenhao } \mathrm{Gu}^{1} \cdot \text { Lühong Zhang }^{1} \cdot \text { Xiaowei Tantai }^{1} \cdot \text { Bin Jiang }}{ }^{1} \cdot$ Huawei Yang ${ }^{1,2} \cdot$ Hongjie Zhang $^{1}$
}

Received: 7 February 2018 / Revised: 4 May 2018 / Accepted: 7 May 2018 / Published online: 28 May 2018

(c) The Author(s) 2018

\begin{abstract}
An organic macromolecule, poly(1-vinylimidazole), with an appropriate polymerization degree was proposed and mixed with water to form a novel aqueous absorbent for $\mathrm{SO}_{2}$ capture. This aqueous solution absorbent has the advantages of simple preparation, good physicochemical properties, environment-friendliness, high ability in deep removal of $\mathrm{SO}_{2}$, and excellent reusability. Moreover, $\mathrm{pH}$-responsive behavior, $\mathrm{pH}$ buffering absorption mechanism, and their synergistic effect on absorption performance were revealed. The solubilities of $\mathrm{SO}_{2}$ in the absorbent were measured in detail, and the results demonstrated excellent absorption capacity and recyclability. Then, mathematic models that describe $\mathrm{SO}_{2}$ absorption equilibrium were established, and the corresponding parameters were estimated. More importantly, on the basis of model and experimental data, the absorption and desorption could maintain high efficiency within a wide operating region. In summary, this work provided a low-cost, efficient, and unique absorbent for $\mathrm{SO}_{2}$ capture and verified its technical feasibility in industrial application.
\end{abstract}

Keywords Poly(1-vinylimidazole $) \cdot \mathrm{pH}$ buffer $\cdot \mathrm{pH}$ responsibility $\cdot \mathrm{SO}_{2}$ capture $\cdot$ Flue gas desulfurization

\section{Introduction}

Combustion of fossil fuels leads to a large amount of sulfur dioxide $\left(\mathrm{SO}_{2}\right)$ emission, which causes serious environmental problems and is harmful to human health [1]. Therefore, a crucial task is to reduce $\mathrm{SO}_{2}$ emission through flue gas desulfurization (FGD) on account of the principles of sustainable development and green chemistry [2].

Among all the FGD technologies, wet desulfurization [3, $4]$ and dry desulfurization $[5,6]$ are widely used in practice. The efficiency of dry desulfurization is lower than that of wet desulfurization, thereby preventing the large-scale

Electronic supplementary material The online version of this article (https://doi.org/10.1007/s12209-018-0168-0) contains supplementary material, which is available to authorized users.

Lühong Zhang

zhanglvh@tju.edu.cn

$\triangle$ Huawei Yang

huaweiyang@tju.edu.cn

1 School of Chemical Engineering and Technology, Tianjin University, Tianjin 300350, China

2 School of Chemistry and Materials Science, Ludong University, Yantai 264025, China application of dry desulfurization. Limestone-gypsum as a kind of absorbent in one of the wet desulfurization methods has been widely used in practice [7-9]. However, limestonegypsum has various inherent disadvantages, such as the production of a large amount of wastewater, high operating cost, useless byproducts that cause secondary pollutants, and intensive energy consumption. Another widely adopted wet desulfurization method is the use of organic amine, such as ethylenediamine [10], as absorbent in FGD. This method has a high desulfurization efficiency, and $\mathrm{SO}_{2}$ can be desorbed from the system by heating so that the absorbents can be recycled. $\mathrm{N}$-methylimidazole and $\mathrm{N}$-methylpyrrolidone also showed great performance in $\mathrm{SO}_{2}$ absorption [11]. However, the large loss of the absorption agent is inevitable because the organic solvents will volatilize into the gas stream, especially in the desorption process. The development of renewable and efficient absorbents with the absence of byproducts is highly valued for industrial application.

Recently, ionic liquids (ILs) have attracted widespread attention as promising absorbents for $\mathrm{SO}_{2}$ removal and capture due to their unique properties [12-14], such as negligible vapor pressure, high thermal stability, and tunable structure. Wu et al. [15] first reported an IL-1,1,3,3-tetramethylguanidinium lactate ([TMG]L) for $\mathrm{SO}_{2}$ absorption from a gas mixture of $\mathrm{SO}_{2}$ and $\mathrm{N}_{2}$, and the result showed 
that $1 \mathrm{~mol}$ [TMG]L could selectively capture $0.978 \mathrm{~mol} \mathrm{SO}_{2}$ at $40{ }^{\circ} \mathrm{C}$. Later, many other ILs, including hydroxyl ammonium ILs [16, 17], ether-functionalized ILs [18-20], imidazolium-based ILs [21-23], guanidinium-based ILs [24-26], pyridinium-based ILs [27, 28], anion-functionalized ILs [29, 30], and, more recently, deep eutectic solvents [31-33], were investigated for $\mathrm{SO}_{2}$ absorption.

Absorption capacity and absorption rate are two important aspects in assessing the absorption performance of absorbents. Despite the high absorption capacity of ILs, the high viscosities of most task-specific ILs induce the low heat and mass transfer performance of the $\mathrm{SO}_{2}$ absorption process $[34,35]$. In addition, water and $\mathrm{O}_{2}$ are contained in flue gas; thus, part of $\mathrm{SO}_{2}$ can be oxidized into $\mathrm{SO}_{4}{ }^{2-}$ in the FGD process. Moreover, $\mathrm{SO}_{4}{ }^{2-}$ will destroy the structure of the ILs and further affect the reusability of the absorbent [36, 37]. These limitations highlight the significance of developing new absorbents that have low viscosity and can adapt to the complex compositions of flue gas.

To take advantage of the non-volatility of ILs and the applicability of traditional organic amines, poly(1-vinylimidazole) (PVIM), an organic macromolecule with high thermal stability, was proposed and blended with water to form $\mathrm{pH}$ buffering aqueous solutions for $\mathrm{SO}_{2}$ capture. The aqueous absorbents can reversibly and efficiently capture $\mathrm{SO}_{2}$ because of the suitable basicity of each repeated imidazole group in PVIM [11]. The absorptive/desorptive capability and the reusability of the absorbents were investigated in detail. Then, equilibrium models were built according to the absorption mechanism. Parametric analysis was performed based on the models and the experimental data, and correlative thermodynamic parameters were obtained. The application feasibility of this absorbent was examined using the equilibrium models and the parameters.

\section{Experimental Section}

\section{Materials}

$\mathrm{SO}_{2}$ gas $(\geq 99.9 \%)$ and $\mathrm{N}_{2}$ gas $(\geq 99.99 \%)$ were supplied by Tianjin Shengtang Specialty Gases Co., Ltd. Ethanol $(\geq 99.9 \%)$, acetone ( $\geq 99.9 \%)$, cyclohexane ( $\geq 99 \%)$, and azodiisobutyronitrile (AIBN, 99.9\%) were purchased from Aladdin Industrial Corporation. 1-vinylimidazole (VIM) was obtained from Shanghai Meryer Chemical Technology Co., Ltd.

\section{Synthesis of Poly(1-vinylimidazole)}

PVIM was synthesized via conventional free radical polymerization [38]. In a $100 \mathrm{~mL}$ round-bottomed flask, VIM $(10.00 \mathrm{~g})$ was dissolved in a binary mixture of ethanol
$(25.00 \mathrm{~g})$ and cyclohexane $(15.00 \mathrm{~g})$ with a certain amount of AIBN as initiator. The molecular weight of PVIM was regulated by changing the dosage of AIBN, and the molar ratio of AIBN to VIM was selected as 3, 7, and 10\%, respectively. The reaction was placed in a preheated oil bath at $75^{\circ} \mathrm{C}$ with magnetic stirring under nitrogen atmosphere for $24 \mathrm{~h}$. After the reaction, the mixture was precipitated into acetone, and the solid was separated by filtrate. Then, the solid was purified by dissolution in methanol and precipitation with acetone. The steps were repeated two times. Finally, the polymer was dried at $80{ }^{\circ} \mathrm{C}$ under vacuum for $24 \mathrm{~h}$ before use.

\section{Characterization of PVIM}

A series of PVIM with different molecular weights was prepared in this work. Absolute polymer molecular weights were determined using aqueous size exclusion chromatography using Malvern's OMNISEC and summarized in Table 1. The chemical structure of the as-prepared PVIM was confirmed by ${ }^{1} \mathrm{H}$ nuclear magnetic resonance (NMR) spectra and Fourier transform infrared (FTIR) spectra. ${ }^{1} \mathrm{H}$ NMR spectra were measured on a Bruker DPX $500 \mathrm{MHz}$ spectrometer using DMSO as a solvent, and the spectra are illustrated in Fig. S1. FTIR spectra were recorded on a NEXUS870 FTIR spectrometer. The thermal stability of PVIM was investigated using TGA/DSC (STAR ${ }^{\mathrm{e}}$ System, Switzerland) from 0 to $500{ }^{\circ} \mathrm{C}$ at a scan rate of $10{ }^{\circ} \mathrm{C} / \mathrm{min}$ under $\mathrm{N}_{2}$ atmosphere, and the decomposition temperature was determined according to the thermogravimetric analysis (TGA) and differential thermal analysis (DTA) curves.

\section{Preparation of $\mathrm{SO}_{2}$ Absorbents and Determination of Physical Properties}

A range of absorbents was prepared by dissolving PVIM (30 wt \%) with different molecular weights in water (70 wt $\%$ ). The viscosities were measured using a Brookfield DV-II + Pro viscometer, which was supplied by Brookfield Engineering Laboratories. The temperature was controlled by a water bath accurate to $\pm 0.1 \mathrm{~K}$. The viscosities of these

Table 1 Viscosities of the absorbents with different molecular weights

\begin{tabular}{lll}
\hline $\begin{array}{ll}\text { Molar ratio of AIBN to } \\
\text { VIM }(\%)\end{array}$ & $\begin{array}{l}\text { Molecular weight of } \\
\text { PVIM }\end{array}$ & Viscosity (cP) \\
\hline 3 & 5000 & 307.6 \\
7 & 4000 & 194.7 \\
10 & 3100 & 131.6 \\
\hline
\end{tabular}

The absorbents were aqueous solution of PVIM (30 wt $\%$ )

The viscosities were measured at $298.2 \mathrm{~K}$ 
absorbents before absorption at $298.2 \mathrm{~K}$ are listed in Table 1 . The uncertainty of viscosity measurements was estimated to be $\pm 1 \%$.

\section{Absorption of $\mathrm{SO}_{2}$}

The measuring methods employed to determine the absorption of $\mathrm{SO}_{2}$ were similar to those used in other studies, and the diagram of the experimental apparatus is shown in Fig. 1 [39]. The whole test apparatus includes absorption and recording sections. The absorption section consists of two stainless steel chambers, the volumes of which are $161.752 \mathrm{~cm}^{3}\left(V_{1}\right)$ and $88.165 \mathrm{~cm}^{3}\left(V_{2}\right)$, respectively. The bigger chamber, which is called gas reserve, isolates $\mathrm{SO}_{2}$ before it contacts with the absorbent in the smaller chamber. The smaller chamber, which is called equilibrium chamber, is equipped with a magnetic stirrer. The temperature of the chambers is controlled by a water bath with an uncertainty of $\pm 0.1 \mathrm{~K}$. The recording section includes two pressure sensors of $\pm 0.2 \%$ uncertainty (in relation to the full scale of 0-300 kPa), which are connected to a numeric instrument to record the pressure changes of the two chambers online.

In a typical absorption procedure, a known mass ( $w$ ) of solvent was placed in the equilibrium chamber and nitrogen was then purged into the chamber to exclude the air. After a sufficient amount of time, the initial pressure in the equilibrium chamber was noted as $P_{0}$. The air in the gas reserve was exhausted $(<10 \mathrm{~Pa})$, and then the gas reserve received a certain amount of $\mathrm{SO}_{2}$ from the gas cylinder. The pressure was measured as $P_{1}$, which was much larger than $P_{0}$. The needle valve between the two chambers was turned to introduce a certain amount of $\mathrm{SO}_{2}$ into the equilibrium chamber. The absorption equilibrium was considered to have been achieved when the pressure of the equilibrium chamber stayed the same for at least $1 \mathrm{~h}$. At this time, the pressure of the two cells was recorded as $P_{1}^{\prime}$ for the gas reserve and $P_{2}$ for the equilibrium chamber. The $\mathrm{SO}_{2}$ uptake $\left(n\left(P_{\mathrm{s}}\right)\right)$ could be calculated using the following formula:

$n\left(P_{\mathrm{s}}\right)=\rho_{\mathrm{g}}\left(P_{1}, T\right) V_{1}-\rho_{\mathrm{g}}\left(P_{1}^{\prime}, T\right) V_{1}-\rho_{\mathrm{g}}\left(P_{\mathrm{s}}, T\right)\left(V_{2}-V_{\mathrm{a}}\right)$

where $\rho_{\mathrm{g}}(P, T)$, which is obtained from NIST standard reference data [40], represents the density of $\mathrm{SO}_{2}$ in $\mathrm{mol} / \mathrm{cm}^{3}$ at $P$ and $T ; V_{\mathrm{a}}$ is the volume of the absorbent in $\mathrm{cm}^{3}$ at $T$; and $\rho_{\mathrm{g}}\left(P_{\mathrm{s}}, T\right)$ is the density of $\mathrm{SO}_{2}$ gas remaining in the equilibrium chamber when the absorption equilibrium was reached, and it could be calculated by the following equations:

$\rho_{\mathrm{g}}\left(P_{\mathrm{s}}, T\right)=\rho_{12}-\rho_{1}$

$y_{2}=\rho_{\mathrm{g}}\left(P_{\mathrm{s}}, T\right) / \rho_{12}$

where $\rho_{12}$ and $\rho_{1}$ represent the density of the mixed gas and $\mathrm{N}_{2}$ in the equilibrium chamber, respectively; $y_{2}$ is the mole fraction of $\mathrm{SO}_{2}$ in the mixed gas, and $\rho_{12}$ is a function of $y_{2}$. The value of $\rho_{1}$ could be calculated using a generalized second virial coefficient [41]; the formula is as follows:

$Z_{1}=1+\frac{B P_{\mathrm{c}}}{R T_{\mathrm{c}}}\left(\frac{P_{\mathrm{c}}}{T_{\mathrm{c}}}\right)$

$\frac{B P_{\mathrm{c}}}{R T_{\mathrm{c}}}=B^{(0)}+\omega B^{(1)}$

$B^{(0)}=0.083-0.422 / T_{\mathrm{r}}^{1.6}$

$B^{(1)}=0.139-0.172 / T_{\mathrm{r}}^{4.2}$

$\rho_{1}=P_{0} / Z_{1} R T$

where $Z_{1}$ represents the compressibility factor of $\mathrm{N}_{2} ; P_{0}$ is the initial pressure of $\mathrm{N}_{2}$ before $\mathrm{SO}_{2}$ was introduced; and $R$

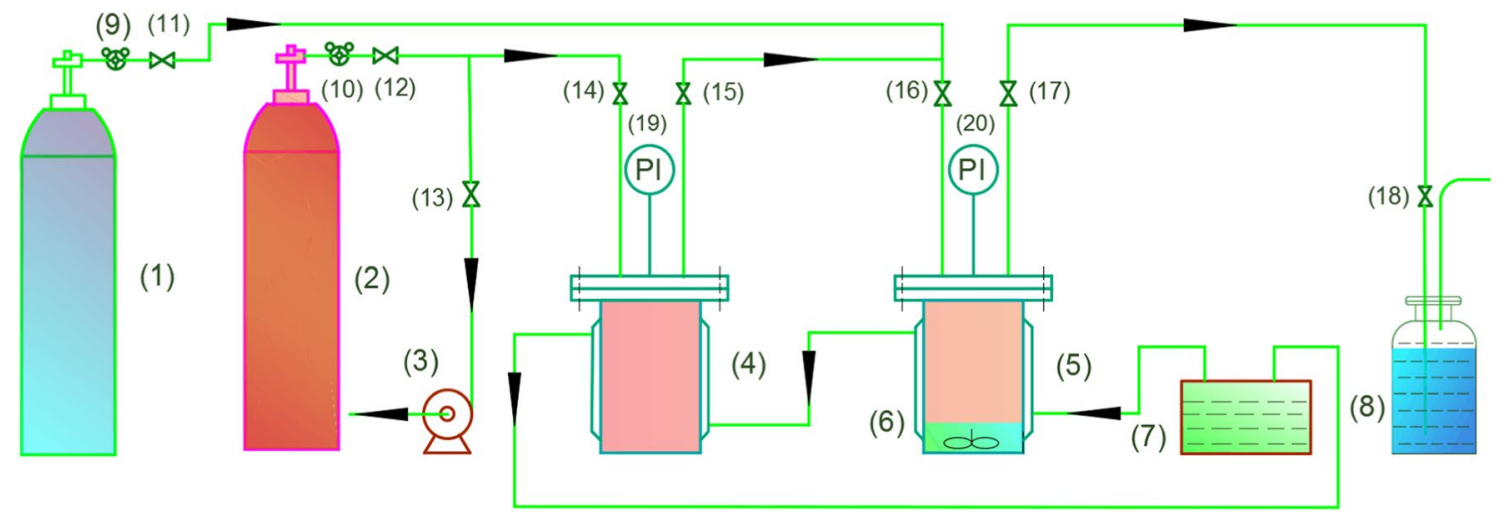

Fig. 1 Diagram of the experimental apparatus of $\mathrm{SO}_{2}$ absorption: (1) $\mathrm{N}_{2}$ gas cylinder; (2) $\mathrm{SO}_{2}$ gas cylinder; (3) vacuum pump; (4) gas reserve chamber; (5) equilibrium chamber; (6) magnetic stirrers; (7) constant temperature water bath; (8) residual gas absorption bottle (sodium hydroxide solution); (9), (10) pressure relief valve; (11)-(18) valve; (19), (20) pressure sensors 
is the molar gas constant $\left(8.314 \mathrm{~J} \cdot \mathrm{mol}^{-1} \cdot \mathrm{K}^{-1}\right)$. The value of $\rho_{12}$ could be calculated using the generalized second virial coefficient of gas mixture; the formula is as follows:

$$
\begin{aligned}
& B_{\mathrm{M}}=y_{1}^{2} B_{11}+2 y_{1} y_{2} B_{12}+y_{2}^{2} B_{22} \\
& y_{1}=1-y_{2}
\end{aligned}
$$

$B_{12}=\frac{R T_{\mathrm{c}_{12}}}{P_{\mathrm{c}_{12}}}\left(B^{(0)}+\omega_{12} B^{(1)}\right)$

$T_{\mathrm{c} 12}=\left(k_{12}-1\right)^{2} \times \sqrt{T_{\mathrm{c} 1} T_{\mathrm{c} 2}}$

$V_{\mathrm{c} 12}=\left(\frac{V_{\mathrm{c} 1}^{1 / 3}+V_{\mathrm{c} 2}^{1 / 3}}{2}\right)^{3}$

$P_{\mathrm{c} 12}=\frac{Z_{\mathrm{c} 12} R T_{\mathrm{c} 12}}{V_{\mathrm{c} 12}}$

$Z_{\mathrm{c} 12}=\frac{Z_{\mathrm{c} 1}+Z_{\mathrm{c} 2}}{V_{\mathrm{c} 12}}$

$\omega_{12}=\frac{\omega_{1}+\omega_{2}}{2}$

$Z_{12}=1+\frac{B_{\mathrm{M}} P}{R T}$

$\rho_{12}=P_{2} / Z_{12} R T$

where $Z_{12}$ represents the compressibility factor of the gas mixture of $\mathrm{SO}_{2}$ and $\mathrm{N}_{2}$ in the equilibrium chamber, and $k_{12}(0.08)$ is the binary interaction parameter. Relevant critical data are listed in Table $\mathrm{S} 1 . \mathrm{SO}_{2}$ was continually introduced into the equilibrium chamber to reach new equilibrium at different pressures. Unabsorbed $\mathrm{SO}_{2}$ was then introduced to the sodium hydroxide solution. The average uncertainty in absorption measurements was estimated to be within $\pm 2 \%$.

\section{pKa Value and Reaction Enthalpy Determination of PVIM}

First, approximately $1 \mathrm{~g}$ PVIM was dissolved in water to form a dilute solution. Then, the solution was titrated by $\mathrm{HCl}$ aqueous solution $(0.1 \mathrm{~mol} / \mathrm{L})$, and $\mathrm{pH}$ values were measured using a PHS-3C-01 pH meter. The uncertainty of the $\mathrm{pH}$ value measurements was \pm 0.01 . The titration experiments were conducted under the temperature range from 25 to $70{ }^{\circ} \mathrm{C}$.

In theory, every imidazole ring of the PVIM can bond with one $\mathrm{H}^{+}$, thus resulting in $\mathrm{pH}$ buffering effects. With the addition of $\mathrm{HCl}, \mathrm{H}^{+}$can spontaneously bond to the position that has the strongest protonation ability, leading to a change in the pKa value of PVIM. To calculate the pKa value evolution and the molar reaction enthalpy $\left(\Delta_{\mathrm{r}} H_{\mathrm{m}}^{0}\right)$, a mathematic model that describes the titration process was built using gPROMS software. The detailed mathematic model is listed in the Supporting Information.

\section{Desorption of $\mathrm{SO}_{2}$ and Recycling of the Absorbents}

The diagram of the experimental apparatus for desorption and recycling of $\mathrm{SO}_{2}$ is shown in Fig. 2. The whole apparatus consists of $\mathrm{SO}_{2}$ and $\mathrm{N}_{2}$ gas cylinders, a glass gas absorption tube (inner diameter of $40 \mathrm{~mm}$ ) with a reflux condenser, a constant temperature oil bath with an uncertainty of $\pm 0.1 \mathrm{~K}$, a pH sensor of \pm 0.01 uncertainty (in relation to the full scale of $0-14$ ), and a residual gas absorption bottle. The absorption tube is equipped with a magnetic stirrer, and the $\mathrm{pH}$ sensor is connected to a numeric instrument to record the $\mathrm{pH}$ evolution of the tube online.

The absorption process was operated at a temperature and a pressure of $298.2 \mathrm{~K}$ and $101.3 \mathrm{kPa}$, respectively. In a
Fig. 2 Diagram of the experimental apparatus for $\mathrm{SO}_{2}$ desorption and recycling: (1) $\mathrm{N}_{2}$ gas cylinder; (2) $\mathrm{SO}_{2}$ gas cylinder; (3) numeric instrument; (4) pH sensor; (5) constant temperature water bath; (6) absorption tube (equipped with a reflux condenser); (7) residual gas absorption bottle (sodium hydroxide solution); (8), (9) pressure relief valve; (10)-(13) valve; (14), (15) rotor flow meter

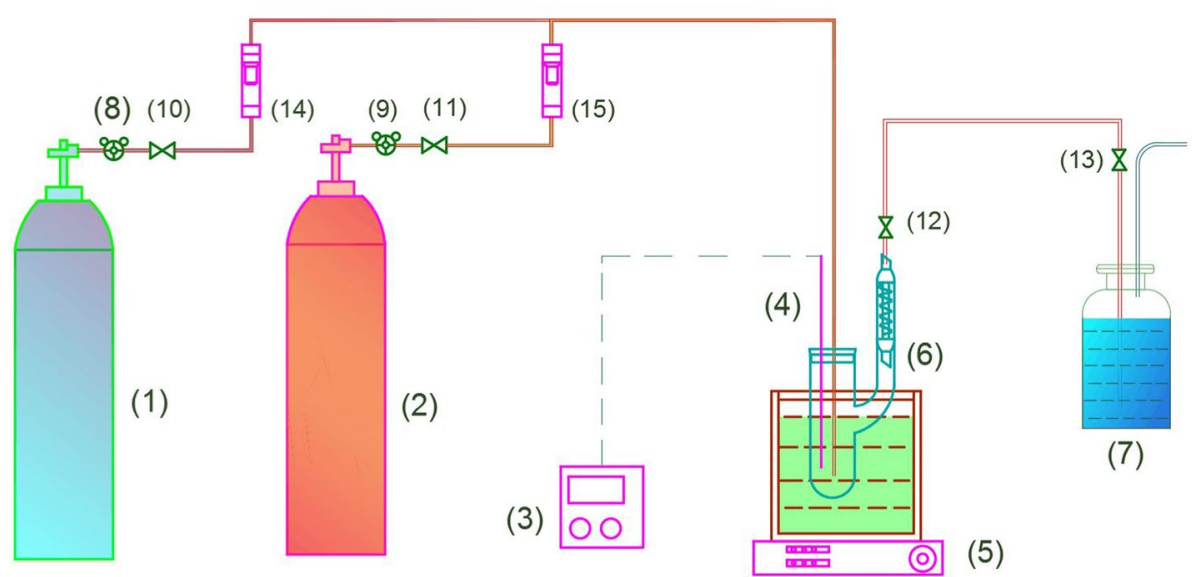


typical procedure, a certain amount of absorbents (30-35 g) was charged into the gas absorption tube. After the air tightness of the experimental apparatus was checked, $\mathrm{N}_{2}$ gas was released at a rate of $30 \mathrm{~mL} / \mathrm{min}$ for $30 \mathrm{~min}$ to drive away the air in the experimental apparatus. Then, $\mathrm{N}_{2}$ gas was cut off by closing the valve, and $\mathrm{SO}_{2}$ gas was bubbled through the gas absorption tube at a rate of $40 \mathrm{~mL} / \mathrm{min}$. The weight changes of the tube combined with the absorbent during the absorption process were monitored using an electron analytical balance (Precision \& Scientific FA2004, Shanghai, China) with an accuracy of $\pm 0.0001 \mathrm{~g}$, and the molar ratio of absorbed $\mathrm{SO}_{2}$ to VIM could be measured. The absorption equilibrium was considered to be reached when the $\mathrm{pH}$ value no longer changed, and then $\mathrm{SO}_{2}$ gas was cut off.

The desorption of $\mathrm{SO}_{2}$ from the absorbents was conducted by increasing the temperature of the oil bath to $373.2 \mathrm{~K}$. The desorption equilibrium was considered to be reached when the $\mathrm{pH}$ value did not change. The experiments of the absorption $(298.2 \mathrm{~K}$ and $101.3 \mathrm{kPa})$ and desorption $(373.2 \mathrm{~K}$ and $101.3 \mathrm{kPa}$ ) cycles were repeated five times to test the reusability of the PVIM solution. Afterwards, the water in the absorbent was removed by rotary evaporation. Furthermore, to evaluate the absorption/desorption efficiency, another mathematic model that describes the absorption/desorption equilibrium is established and listed in the Supporting Information.

\section{Results and Discussion}

\section{Physical Properties of the Absorbents}

The molecular weights of PVIM synthesized in different conditions and the viscosities of the corresponding absorbents are listed in Table 1. The viscosity of the absorbents under the same concentration decreased with the decrease in the molecular weights of the PVIM. As is well accepted, low viscosity is favorable to the absorption efficiency of $\mathrm{SO}_{2}$. Thus, the absorbent with the lowest viscosity, which means the PVIM whose molecular weight is 3100 , was used in the subsequent experiments.

The $\mathrm{pH}$-responsive properties of many polymers were frequently reported to have physicochemical properties that can spontaneously change with the variation of $\mathrm{pH}$ value in a narrow range $[42,43]$. Hence, the $\mathrm{pH}$ values and the corresponding viscosities of the absorbents during the absorption process at different temperatures ranging from 298.2 to 318.2 $\mathrm{K}$ were measured and listed in Table 2.

Notably, the viscosities not only decreased with the increase in temperature but also dramatically decreased when the absorbents changed from alkaline to acidic. For example, the viscosity at $298.2 \mathrm{~K}$ is $131.6 \mathrm{cP}$ when $\mathrm{pH}$ is 9.1 and $2.42 \mathrm{cP}$ when $\mathrm{pH}$ is 5.0 , which is comparable
Table 2 Viscosities of the absorbents with various $\mathrm{pH}$ values

\begin{tabular}{lccc}
\hline $\mathrm{pH}$ & \multicolumn{3}{l}{ Viscosity $(\mathrm{cP})$} \\
\cline { 2 - 4 } & $298.2 \mathrm{~K}$ & $303.2 \mathrm{~K}$ & $318.2 \mathrm{~K}$ \\
\hline 9.1 & 131.6 & 126.5 & 119.3 \\
7.2 & 16.43 & 15.62 & 14.73 \\
5.0 & 2.42 & 2.03 & 1.85 \\
2.2 & 1.44 & 1.24 & 1.16 \\
\hline
\end{tabular}

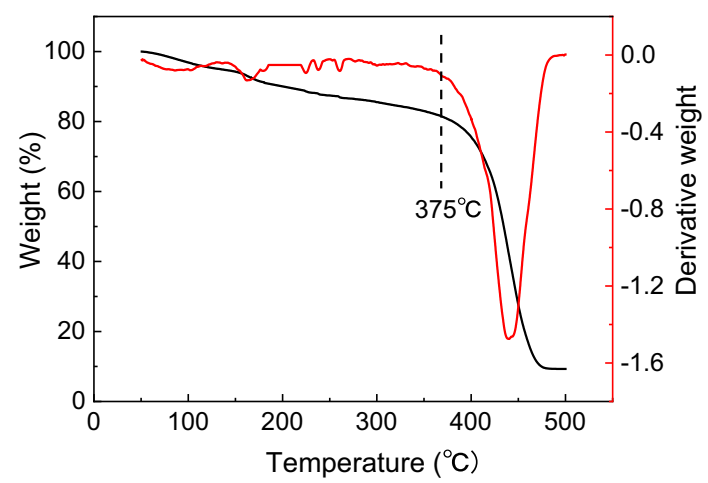

Fig. 3 TGA and DTG curves of PVIM

to that of water $(1.002 \mathrm{cP}$ at $298.2 \mathrm{~K})$ [44]. The reason for this phenomenon was investigated by dynamic light scattering. The size of micelles formed by PVIM could also respond to $\mathrm{pH}$ changes. As shown in Figure S2, the average size of the micelles in the solution varied from 248.1 to $4.2 \mathrm{~nm}$ when the $\mathrm{pH}$ values reduced from 9.1 to 2.2. This change is suspected to be caused by the protonation reaction of the PVIM. Before absorption, PVIM could associate with a little amount of $\mathrm{H}^{+}$ionized by $\mathrm{H}_{2} \mathrm{O}$, thus resulting in the original solution being alkaline. However, the strong hydrogen bonding interactions between the partial protonated polymers would cause a tight association. As a result, the PVIM aqueous solution before absorption exhibited a relatively high viscosity. When the concentration of the $\mathrm{H}^{+}$continued to increase during the absorption of $\mathrm{SO}_{2}$, more imidazole units of PVIM became protonated, which resulted in the weakening of association between polymers and enhanced the solvation interaction in water. Consequently, the absorbents possess notable $\mathrm{pH}$-responsive properties. Moreover, lower viscosity can enhance the phase transfer between the gas-liquid two-phase and is favorable to the efficient absorption of $\mathrm{SO}_{2}$.

To verify the thermal stability of PVIM, the TGA and DTA curves of the PVIM are shown in Fig. 3. The PVIM first showed an obvious loss of weight at $375{ }^{\circ} \mathrm{C}$, which means that the PVIM is stable enough under the operating conditions. 


\section{Absorption of $\mathrm{SO}_{2}$}

\section{Absorption Mechanism}

The proposed $\mathrm{SO}_{2}$ absorption mechanism is illustrated in Scheme 1. Primarily, the gaseous $\mathrm{SO}_{2}$ was dissolved in water, and the dissolved $\mathrm{SO}_{2}$ could form $\mathrm{H}_{2} \mathrm{SO}_{3}$ through a hydration reaction. Then, $\mathrm{H}_{2} \mathrm{SO}_{3}$ was ionized to $\mathrm{HSO}_{3}{ }^{-}$, $\mathrm{SO}_{3}{ }^{2-}$, and $\mathrm{H}^{+}$, while the imidazole groups in each repeated unit could effectively bond the $\mathrm{H}^{+}$through a protonated reaction, thus significantly promoting the solubility of $\mathrm{SO}_{2}$ in the absorbent. To confirm the proposed absorption mechanism, the FTIR spectra of the absorbents before and after $\mathrm{SO}_{2}$ absorption were studied, and the results are shown in Fig. 4. As can be seen from Fig. 4, three new peaks appeared at 961,1151 , and $1545 \mathrm{~cm}^{-1}$ after the absorption of $\mathrm{SO}_{2}$. The absorption bond at $961 \mathrm{~cm}^{-1}$ corresponds to $\mathrm{S}-\mathrm{O}$ stretching vibration in $\mathrm{SO}_{3}{ }^{2-}, \mathrm{HSO}_{3}{ }^{-}$, or similar species, thereby indicating the chemical interactions between $\mathrm{SO}_{2}$ and the mixed absorbent [45]. The other peak at $1151 \mathrm{~cm}^{-1}$ can be assigned to the antisymmetric stretch of the dissolved $\mathrm{SO}_{2}$, while the peak at $1545 \mathrm{~cm}^{-1}$ could be attributed to stretches of $\mathrm{C}-\mathrm{C}$ and $\mathrm{C}-\mathrm{N}$ in the ring after protonation [46]. Furthermore, a series of dispersed bonds in the region of $2800-2400 \mathrm{~cm}^{-1}$ after absorption could be assigned to $\mathrm{NH}^{+}$[47]. In sum, the results of FTIR clearly prove the proposed absorption mechanism.

\section{Absorption Capacity}

To investigate the absorption capability of the absorbent, the equilibrium solubility of $\mathrm{SO}_{2}$ in the absorbent was determined against $\mathrm{SO}_{2}$ partial pressure at temperatures ranging from 298.2 to $328.2 \mathrm{~K}$, and the results are shown in Fig. 5 (the solubility data are presented in Table S2). A detail that should be noted first is that each absorption equilibrium could be reached within 5 min, thereby indicating the low transfer resistance of the absorbent, which was attributed to the reduced viscosities in acidic conditions. The absorption isotherms shown in Fig. 5 demonstrated good absorption capability. The solubility of $\mathrm{SO}_{2}$ in the absorbent increased drastically with the increasing $\mathrm{SO}_{2}$ partial pressure under

$$
\begin{aligned}
\mathrm{SO}_{2(\mathrm{gas})} & \rightleftharpoons \mathrm{SO}_{2(\mathrm{aq})} \\
\mathrm{SO}_{2(\mathrm{aq})}+\mathrm{H}_{2} \mathrm{O} & \rightleftharpoons \mathrm{H}^{+}+\mathrm{HSO}_{3}^{-} \\
\mathrm{HSO}_{3}^{-} & \rightleftharpoons \mathrm{H}^{+}+\mathrm{SO}_{3}{ }^{2-} \\
\mathrm{PVIM}^{-} \mathrm{H}^{+} & \rightleftharpoons \mathrm{PVIMH}^{+}
\end{aligned}
$$

Scheme 1 Absorption mechanism of $\mathrm{SO}_{2}$ in the absorbents

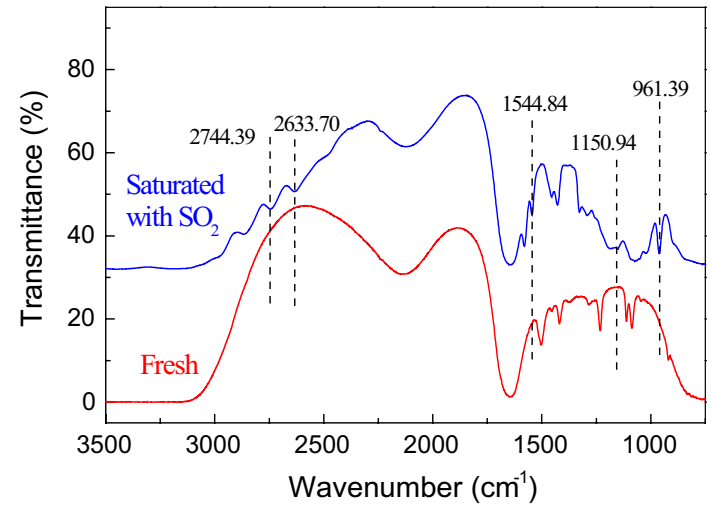

Fig. 4 FTIR spectra of fresh absorbent and absorbent saturated with $\mathrm{SO}_{2}$

low pressure $(0-10.0 \mathrm{kPa})$, whereas it increased gradually and almost linearly under high pressure (10.0-100.0 kPa). For example, the $\mathrm{SO}_{2}$ absorption capacity at $298.2 \mathrm{~K}$ is $0.431 \mathrm{~mol} \mathrm{SO}_{2}$ per kg absorbents at $0.3 \mathrm{kPa}, 1.719 \mathrm{~mol}$ $\mathrm{SO}_{2}$ per kg absorbents at $1.7 \mathrm{kPa}$, and $2.215 \mathrm{~mol} \mathrm{SO}_{2}$ per $\mathrm{kg}$ absorbents at $9.4 \mathrm{kPa}$. The large $\mathrm{SO}_{2}$ solubility at low pressures can be primarily attributed to chemical absorption according to the proposed absorption mechanism. The strong bonding of $\mathrm{H}^{+}$with PVIM could enhance the ionization of $\mathrm{H}_{2} \mathrm{SO}_{3}$ and significantly improve the content of $\mathrm{HSO}_{3}{ }^{-}$and $\mathrm{SO}_{3}{ }^{2-}$ in the system, while the linear increment of $\mathrm{SO}_{2}$ solubility at high pressures was due to the complete protonation of PVIM.

In view of the relatively low $\mathrm{SO}_{2}$ partial pressure in flue gas, a strong chemical interaction is essential, while the reaction equilibrium is always sensitive to temperature. As can be seen from Fig. 5, the increase in temperature has a negative influence on the solubility of $\mathrm{SO}_{2}$ in the absorbent. For example, the solubility at $99.2 \mathrm{kPa}$ is 3.409 and $2.468 \mathrm{~mol}$ $\mathrm{SO}_{2}$ per kg absorbent at 298.2 and $328.2 \mathrm{~K}$, respectively.

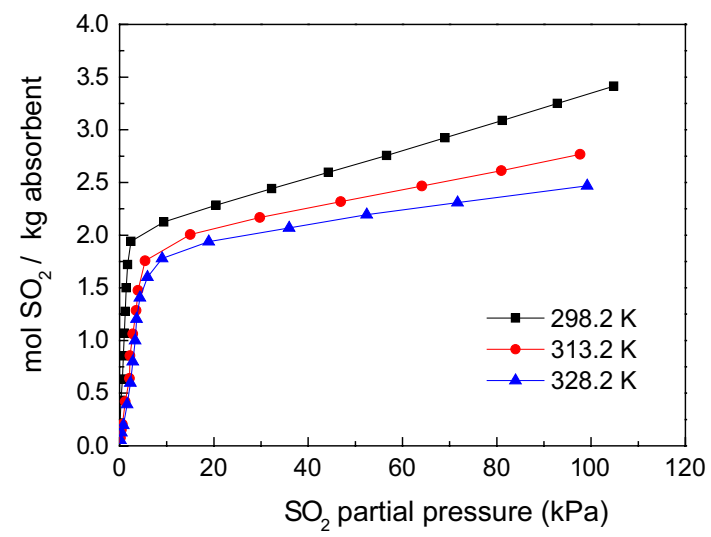

Fig. 5 Absorption isotherm of $\mathrm{SO}_{2}$ by the absorbent at different temperatures 
This phenomenon was consistent with the absorption mechanism we presented and the results obtained in most cases $[48,49]$. Low temperature is not only beneficial to physical absorption but also shifts the protonation reaction equilibrium toward a positive direction. The results also indicated that the absorbed $\mathrm{SO}_{2}$ could be released at high temperature.

In this absorbent, PVIM, as the major absorption component, could achieve the effective capture of $\mathrm{SO}_{2}$ through the $\mathrm{pH}$ buffering effect, whereas water, a green solvent, was employed to realize the dissolution of PVIM and provide the reaction environment for the absorption. Given its easy preparation, low cost, and environment-friendliness, the absorbent can be regarded as a promising candidate for application. Moreover, considering that $\mathrm{SO}_{2}$ capture is a continuous process of absorption-desorption, the suitable alkalinity of PVIM, which is the key point to enable the desorption at high temperature, was investigated in detail in the following sections.

\section{Thermodynamic Analysis}

To calculate the reaction equilibrium constant $(K)$, acidity coefficient ( $\mathrm{pKa}$ ), and the thermodynamic parameters of the protonation reaction of PVIM, acid titration experiments at different temperatures were conducted, and the experiment results are shown in Fig. 6. A corresponding reaction equilibrium mathematic model to describe the acid titration process was built using gPROMS software.

According to the absorption mechanism, PVIM could promote the capture of $\mathrm{SO}_{2}$ through the reversible protonation reaction, while, as a macromolecule, the already protonated imidazole units would influence the bonding ability toward $\mathrm{H}^{+}$ of other surrounding units via the inductive effect. Hence, we can reasonably consider that the $\mathrm{pKa}$ value of the macromolecule would vary with the increment of the protonation degree.

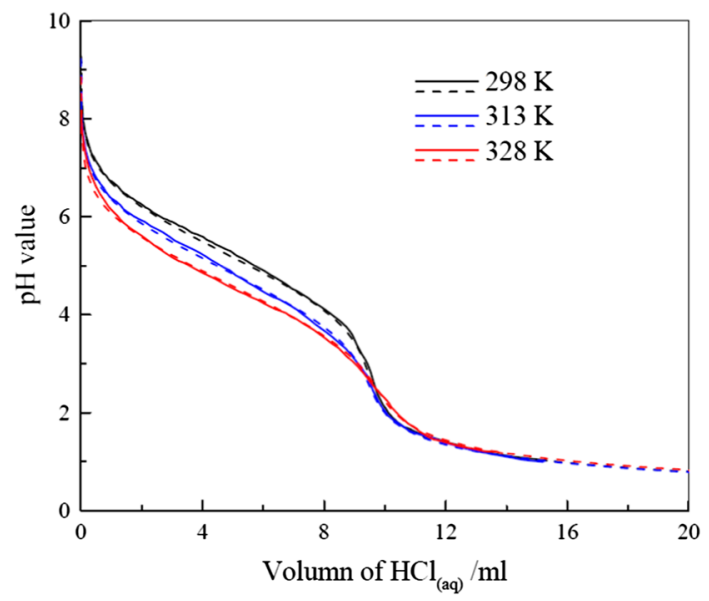

Fig. $6 \mathrm{pH}$ variation during $\mathrm{HCl}_{(\mathrm{aq})}$ titration process at 298, 313, and $328 \mathrm{~K}$ (solid line: experimental data; dash line: predicted results)
Given that the protonation reaction is an equilibrium process, the $\mathrm{H}^{+}$could spontaneously bond with the imidazole units that have the strongest bonding ability. Therefore, for a single PVIM molecule with a certain protonation degree, its corresponding pKa value is constant (all the PVIM are assumed to have the same molecular weight). Thus, the average protonation degree of the PVIM is defined as:

$\omega=c_{\mathrm{VIMH}^{+}} /\left(c_{\mathrm{VIM}}+c_{\mathrm{VIMH}^{+}}\right)$

At a certain $\omega$, the calculated pKa value can be approximately considered as the pKa value of a single PVIM molecule with the same protonation degree.

Through parametric analysis of the experimental results, the pKa values of the PVIM variation with the change in the protonation degree at different temperatures were calculated, and the results are illustrated in Fig. 7. The pKa values of the PVIM decreased with the reduction of $\mathrm{pH}$ values of the aqueous solution and with the increase in the protonation degree of the PVIM. As can be seen in Fig. 7, the pKa value decreased from 5.98 before the titration experiments to 4.46 when the protonation degree was $100 \%$ at $298 \mathrm{~K}$. Thus, the pKa value of the PVIM ranges from 4.46 to 5.98. The pKa value is known to reflect the ability to dissociate $\mathrm{H}^{+}$. The decrease in the $\mathrm{pKa}$ value along with the increase in the protonation degree indicates that the interaction between $\mathrm{H}^{+}$and PVIM becomes weaker. Subsequently, the molar reaction enthalpy, which is crucial for the design of industrial processes, was estimated using the van der Hoff equation. Furthermore, the molar Gibbs energy of reaction and molar reaction entropy can be calculated using Eqs. (20) and (21).

$\Delta_{\mathrm{r}} G_{\mathrm{m}}^{0}=-R T \ln K^{0}$

$\Delta_{\mathrm{r}} S_{\mathrm{m}}^{0}=\left(\Delta_{\mathrm{r}} H_{\mathrm{m}}^{0}-\Delta_{\mathrm{r}} G_{\mathrm{m}}^{0}\right) / T$

With the pKa values integrated into these equations, the average values of $\Delta_{\mathrm{r}} H_{\mathrm{m}}^{0}, \Delta_{\mathrm{r}} S_{\mathrm{m}}^{0}$ and $\Delta_{\mathrm{r}} G_{\mathrm{m}}^{0}$ are presented in

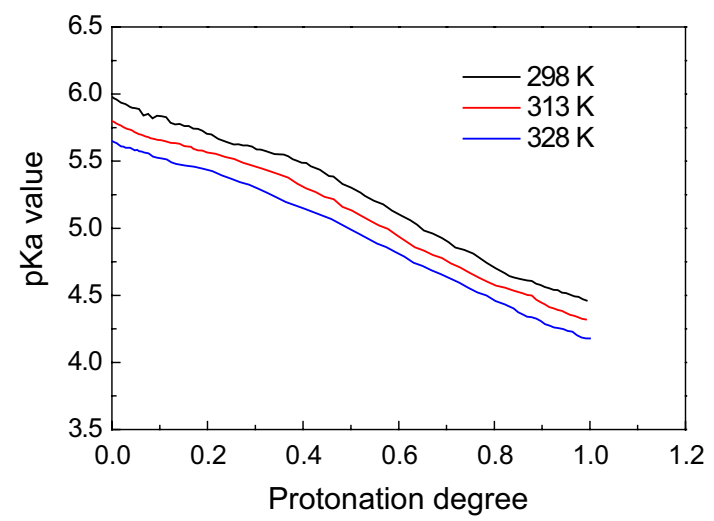

Fig. 7 Relationship of $\mathrm{pKa}$ value versus protonation degree at different temperatures 
Table 3 Average molar reaction enthalpy, molar Gibbs energy of reaction, and molar reaction entropy at $298 \mathrm{~K}$

\begin{tabular}{llll}
\hline & $\Delta_{\mathrm{r}} H_{\mathrm{m}}^{0}\left(\mathrm{~kJ} \mathrm{~mol}^{-1}\right)$ & $\Delta_{\mathrm{r}} G_{\mathrm{m}}^{0}\left(\mathrm{~kJ} \mathrm{~mol}^{-1}\right)$ & $\Delta_{\mathrm{r}} S_{\mathrm{m}}^{0}\left(\mathrm{~J} \mathrm{~mol}^{-1} \mathrm{~K}^{-1}\right)$ \\
\hline $\mathrm{PVIMH}^{+}$ & $-40.30 \pm 5$ & $-34.13 \pm 1.14$ & $-20.69 \pm 17.20$ \\
\hline
\end{tabular}

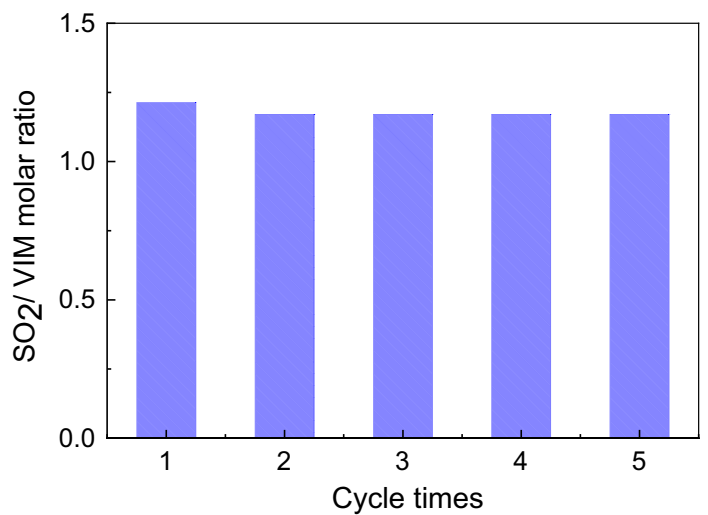

Fig. 8 Reusability of the absorbents in $\mathrm{SO}_{2}$ absorption for five cycles

Table 3. Furthermore, in accordance with the calculated parameters and the mathematic model, the $\mathrm{pH}$ variation with the addition amount of $\mathrm{HCl}$ was obtained and illustrated in Fig. 6. The calculated results showed good agreement with the experimental data, which demonstrates the accuracy of calculated parameters.

\section{Desorption of $\mathrm{SO}_{2}$ and Reuse of the Absorbent}

On the basis of previous analysis, the $\mathrm{pH}$ value of the system is a significant factor in evaluating the absorptive amount of $\mathrm{SO}_{2}$. Hence, in this work, absorption/desorption capability and technological feasibility were studied by measuring the variation of the $\mathrm{pH}$ value and the weight change of the absorbent in the repeated absorptive/desorptive process. Experiments on the absorption and desorption cycles of $\mathrm{SO}_{2}$ were conducted five times. The absorption or desorption equilibrium was considered to be achieved when the $\mathrm{pH}$ value of the absorbents no longer changed. After five cycles, almost no decline in the equilibrium absorption capacity of $\mathrm{SO}_{2}$ occurred (see Fig. 8).

The solubility is $1.21 \mathrm{~mol} \mathrm{SO}_{2}$ per mole VIM for the first time and $1.17 \mathrm{~mol} \mathrm{SO}_{2}$ per mole VIM in the subsequent cycles. The desorption efficiency could reach $96.6 \%$ after the desorption. The slightly incomplete desorption may be due to the reflux water bringing back a small amount of $\mathrm{SO}_{2}$. The $\mathrm{pH}$ changes in the absorption and desorption process are shown in the Supporting Information. The curves of the $\mathrm{pH}$ change with time are almost the same (see Figs. S3 and S4),

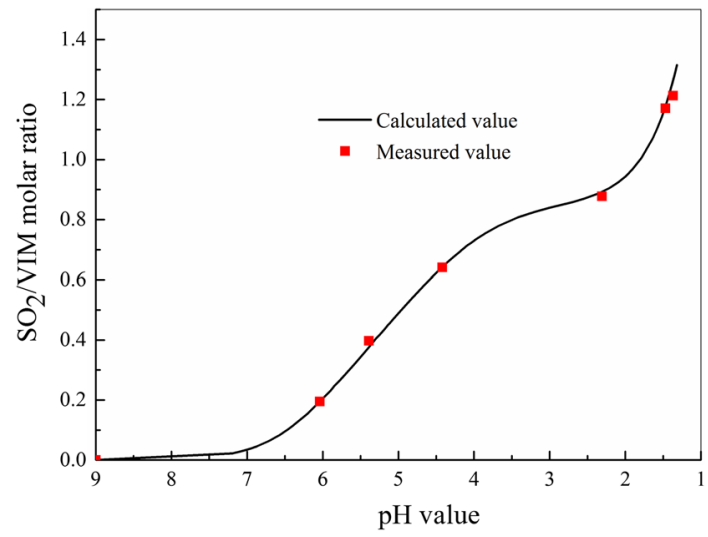

Fig. 9 Calculated and measured values of the molar ratio of $\mathrm{SO}_{2}$ to VIM

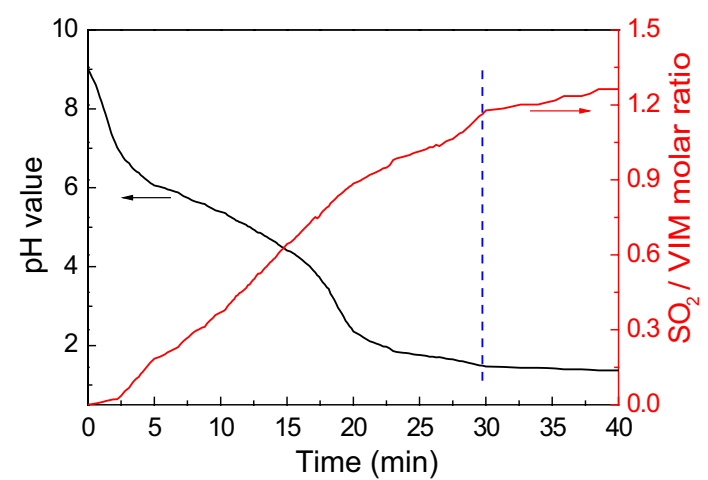

Fig. 10 Variations of $\mathrm{pH}$ and solubility of $\mathrm{SO}_{2}$ with time in the absorption process

which also proves that the absorption of $\mathrm{SO}_{2}$ in the mixed absorbent is highly reversible and the absorbed $\mathrm{SO}_{2}$ can be easily stripped out by heating.

According to the absorption mechanism, the absorptive amount of the $\mathrm{SO}_{2}$ in the absorbents is closely related to the $\mathrm{pH}$ value and temperature, and can be calculated using the absorption equilibrium model and the obtained thermodynamic parameters. First, to validate the model, the absorptive amount of $\mathrm{SO}_{2}$ that varied with the $\mathrm{pH}$ changes at $298 \mathrm{~K}$ was calculated and compared with the experimental data. As shown in Fig. 9, all the measured values are in good agreement with the calculated ones, which proves that the absorption equilibrium model is reliable. Taking the $\mathrm{pH}$ variation data into the model, the corresponding absorptive amount could be estimated.

The absorption of $\mathrm{SO}_{2}$ in the absorbents at $298 \mathrm{~K}$ over time was estimated. As shown in Fig. 10, the absorption capacity had an approximately linear increase with time in the initial 30 min with the corresponding $\mathrm{pH}$ value interval of 9.02-1.51, which means that the absorbent could achieve 
efficient capture of $\mathrm{SO}_{2}$ in this $\mathrm{pH}$ region. However, the absorption efficiency decreased dramatically after $30 \mathrm{~min}$, which suggested that the reactive absorption had been completed when the $\mathrm{pH}$ value was lower than 1.51. Similarly, the optimum $\mathrm{pH}$ value interval in the desorption process could be obtained.

The desorption of $\mathrm{SO}_{2}$ from the absorbents over time was conducted at $383 \mathrm{~K}$ under the condition of heating reflux. High temperature has an inhibiting effect on the protonation reaction of PVIM, while the decrease in the partial pressure of $\mathrm{SO}_{2}$ in the gas phase caused by steam stripping is the immediate cause of efficient desorption. With the proceeding of the desorption process, the desorption driving force decreased, and the pKa value of the PVIM increased gradually. Hence, the desorption rate gradually reduced as time proceeded. As shown in Fig. 11, in the initial 40 min of the desorption process and when the $\mathrm{pH}$ value of the system was lower than 4.80, the desorption efficiency could maintain a relatively high level and the residual amount was less than $10 \%$. Therefore, the $\mathrm{pH}$ interval of $1.42-4.80$ was considered a proper desorption operation range.

According to the absorption and desorption curves shown in Figs. 10 and 11, in a continuous operation process, both the absorption and desorption rates could maintain high when the $\mathrm{pH}$ value ranged from 1.51 to 4.80 . In this region, the ratio of the available absorptive amount can reach up to $80 \%$, the corresponding gas amount was $2.99 \mathrm{~kg}$ per mol absorbent, and, more importantly, the viscosity of the absorbent was comparable to that of water. All these results proved the applicability of the absorbent in the $\mathrm{SO}_{2}$ capture process.

After five absorption-desorption cycles, the water in the absorbent was removed by rotary evaporation. The residual PVIM was dried under vacuum and analyzed by FTIR. As shown in Fig. 12, no noticeable change can be detected after the cycles, as indicated by a comparison with the fresh

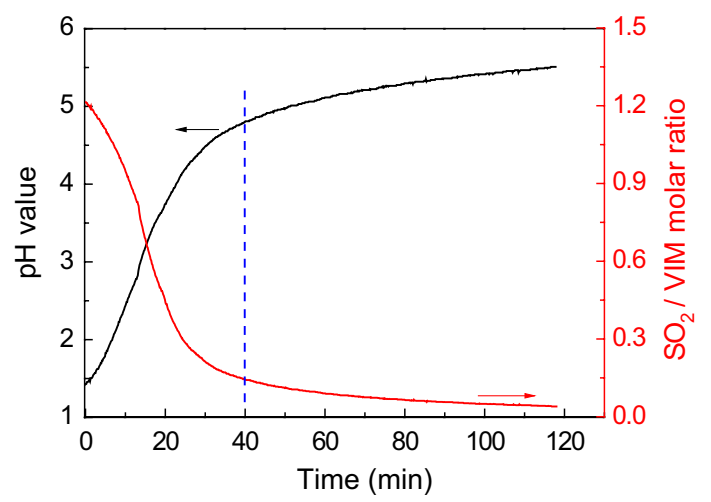

Fig. 11 Variations of $\mathrm{pH}$ and solubility of $\mathrm{SO}_{2}$ with time in the desorption process

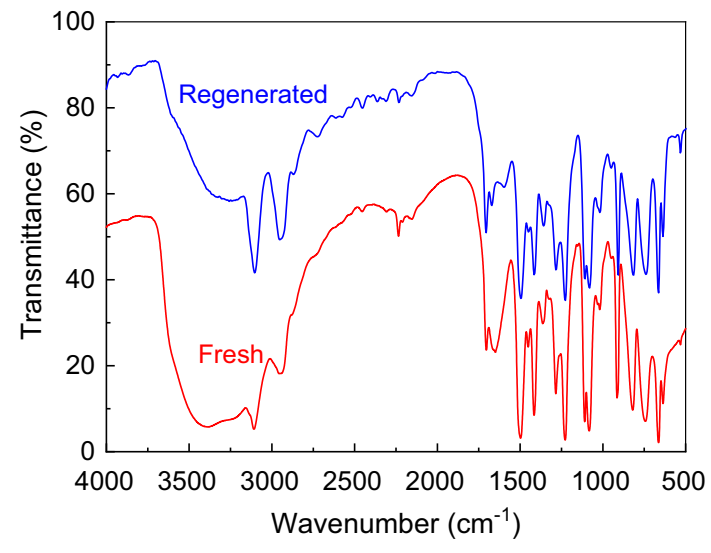

Fig. 12 FTIR spectra of PVIM before use and after regenerating

PVIM, which further proves the excellent stability and reusability of the absorbent.

\section{Conclusion}

In this work, a novel macromolecule absorbent that was prepared by blending PVIM and water is first proposed for $\mathrm{SO}_{2}$ absorption. This $\mathrm{pH}$ buffering absorbent combines the advantages of the non-volatility of ILs and the applicability of traditional organic amines. Furthermore, the unique pH-responsive characteristic of the absorbent provides it with a suitable physicochemical property in the absorption process. The results of the absorption and desorption experiments showed that the absorbent can capture $\mathrm{SO}_{2}$ efficiently at low partial pressure and release $\mathrm{SO}_{2}$ easily by heating reflux. As verified by FTIR, the reversible absorption of $\mathrm{SO}_{2}$ was attributed to the reversible protonation reaction of PVIM due to its moderate alkalinity. Moreover, no obvious reduction in absorption capacity and chemical structure change were detected after several cycles, which demonstrated the reusability and recyclability of the absorbent. According to the thermodynamic analysis, the pKa value of the PVIM decreased with the increase in the protonation degree because of the inductive effect of the protonated units, but the $\mathrm{pKa}$ value still remained within an applicable range. With the use of the thermodynamic parameters, a technical feasibility study was conducted, and the absorbent was proven to be an excellent candidate for $\mathrm{SO}_{2}$ capture in industrial application. In summary, this research provides an absorbent that has advantages of simple preparation, good physicochemical properties, environment-friendliness, high ability in deep removal of $\mathrm{SO}_{2}$, and excellent reusability. The unique properties of this absorbent are also revealed.

Acknowledgements This study was supported by the National Key R\&D Program of China (No. 2016YFC0400406). 
Open Access This article is distributed under the terms of the Creative Commons Attribution 4.0 International License (http://creativeco mmons.org/licenses/by/4.0/), which permits unrestricted use, distribution, and reproduction in any medium, provided you give appropriate credit to the original author(s) and the source, provide a link to the Creative Commons license, and indicate if changes were made.

\section{References}

1. Kim KH, Jahan SA, Kabir E (2013) A review on human health perspective of air pollution with respect to allergies and asthma. Environ Int 59:41-52

2. Hansen BB, Kiil S, Johnsson JE et al (2008) Foaming in wet flue gas desulfurization plants: the influence of particles, electrolytes, and buffers. Ind Eng Chem Res 47(9):3239-3246

3. Cordoba P (2015) Status of flue gas desulphurisation (FGD) systems from coal-fired power plants: overview of the physic-chemical control processes of wet limestone FGDs. Fuel 144:274-286

4. Kiil S, Michelsen ML, Dam-Johansen K (1998) Experimental investigation and modeling of a wet flue gas desulfurization pilot plant. Ind Eng Chem Res 37(7):2792-2806

5. Dahlan I, Mohamed AR, Kamaruddin AH et al (2007) Dry $\mathrm{SO}_{2}$ removal process using calcium/siliceous-based sorbents: deactivation kinetics based on breakthrough curves. Chem Eng Technol 30(5):663-666

6. Renedo MJ, Gonzalez F, Pesquera C et al (2006) Study of sorbents prepared from clays and $\mathrm{CaO}$ or $\mathrm{Ca}(\mathrm{OH})_{2}$ for $\mathrm{SO}_{2}$ removal at low temperature. Ind Eng Chem Res 45(10):3752-3757

7. Kaplan V, Wachtel E, Lubomirsky I (2013) Carbonate melt regeneration for efficient capture of $\mathrm{SO}_{2}$ from coal combustion. RSC Adv 3(36):15842-15849

8. Zheng YJ, Kiil S, Johnsson JE (2003) Experimental investigation of a pilot-scale jet bubbling reactor for wet flue gas desulphurisation. Chem Eng Sci 58(20):4695-4703

9. Kang Y, Lu J, Guo J (2017) Treatment of wet FGD wastewater by a modified chemical precipitation method using a solid powder reagent. Trans Tianjin Univ 23(2):110-121

10. Tang ZG, Zhou CC, Chen C (2004) Studies on flue gas desulfurization by chemical absorption using an ethylenediaminephosphoric acid solution. Ind Eng Chem Res 43(21):6714-6722

11. Huang K, Xia S, Zhang XM et al (2014) Comparative study of the solubilities of $\mathrm{SO}_{2}$ in five low volatile organic solvents (sulfolane, ethylene glycol, propylene carbonate, $N$-methylimidazole, and $N$-methylpyrrolidone). J Chem Eng Data 59(4):1202-1212

12. Rogers RD, Seddon KR (2003) Ionic liquids-solvents of the future? Science 302(5646):792-793

13. Severa G, Bethune K, Rocheleau $\mathrm{R}$ et al (2015) $\mathrm{SO}_{2}$ sorption by activated carbon supported ionic liquids under simulated atmospheric conditions. Chem Eng J 265:249-258

14. Heldebrant DJ, Koech PK, Yonker CR (2010) A reversible zwitterionic $\mathrm{SO}_{2}$-binding organic liquid. Energy Environ Sci 3(1):111-113

15. Wu W, Han B, Gao H et al (2004) Desulfurization of flue gas: $\mathrm{SO}_{2}$ absorption by an ionic liquid. Angew Chem Int Ed 43(18):2415-2417

16. Huang $\mathrm{K}, \mathrm{Lu} \mathrm{JF}, \mathrm{Wu} \mathrm{YT}$ et al (2013) Absorption of $\mathrm{SO}_{2}$ in aqueous solutions of mixed hydroxylammonium dicarboxylate ionic liquids. Chem Eng J 215-216:36-44

17. Yuan XL, Zhang SJ, Lu XM (2007) Hydroxyl ammonium ionic liquids: synthesis, properties, and solubility of $\mathrm{SO}_{2}$. J Chem Eng Data 52(2):596-599

18. Hong SY, Im J, Palgunadi J et al (2011) Ether-functionalized ionic liquids as highly efficient $\mathrm{SO}_{2}$ absorbents. Energy Environ Sci 4(5):1802-1806
19. Wang J, Zeng SJ, Bai L et al (2014) Novel ether-functionalized pyridinium chloride ionic liquids for efficient $\mathrm{SO}_{2}$ capture. Ind Eng Chem Res 53(43):16832-16839

20. Yu FL, Liu CY, Yuan B et al (2016) Energy-efficient extractive desulfurization of gasoline by polyether-based ionic liquids. Fuel 177:39-45

21. Li N, Wang F, Zhang ZQ et al (2014) Synthesis and desulfurization performance of functional silica gel modified by polymeric 1-vinyl-3-ethylimidazolium tetrafluoroborate ionic liquids. Ind Eng Chem Res 53(43):16664-16671

22. Firaha DS, Kavalchuk M, Kirchner B (2015) SO solvation in the 1-ethyl-3-methylimidazolium thiocyanate ionic liquid by incorporation into the extended cation-anion network. J Solut Chem 44(3-4):838-849

23. Jiang XC, Nie Y, Li CX et al (2008) Imidazolium-based alkylphosphate ionic liquids: a potential solvent for extractive desulfurization of fuel. Fuel 87(1):79-84

24. Zhang ZM, Wu LB, Dong J et al (2009) Preparation and $\mathrm{SO}_{2}$ sorption/desorption behavior of an ionic liquid supported on porous silica particles. Ind Eng Chem Res 48(4):2142-2148

25. Lu X, Yu J, Wu J et al (2015) Novel guanidinium-based ionic liquids for highly efficient $\mathrm{SO}_{2}$ capture. J Phys Chem B 119(25):8054-8062

26. Huang J, Riisager A, Wasserscheid P et al (2006) Reversible physical absorption of $\mathrm{SO}_{2}$ by ionic liquids. Chem Commun 38:4027-4029

27. Zeng SJ, He HY, Gao HS et al (2015) Improving $\mathrm{SO}_{2}$ capture by tuning functional groups on the cation of pyridinium-based ionic liquids. RSC Adv 5(4):2470-2478

28. Zeng SJ, Gao HS, Zhang XC et al (2014) Efficient and reversible capture of $\mathrm{SO}_{2}$ by pyridinium-based ionic liquids. Chem Eng $\mathrm{J}$ 251:248-256

29. Tian SD, Hou YC, Wu WZ et al (2013) Absorption of $\mathrm{SO}_{2}$ by thermal-stable functional ionic liquids with lactate anion. RSC Adv 3(11):3572-3577

30. Chen KH, Lin WJ, Yu XN et al (2015) Designing of anion-functionalized ionic liquids for efficient capture of $\mathrm{SO}_{2}$ from flue gas. AIChE J 61(6):2028-2034

31. Zhao Y, Hu GX (2013) Removal of $\mathrm{SO}_{2}$ by a mixture of caprolactam tetrabutyl ammonium bromide ionic liquid and sodium humate solution. RSC Adv 3(7):2234-2240

32. Yang DZ, Hou MQ, Ning $\mathrm{H}$ et al (2013) Efficient $\mathrm{SO}_{2}$ absorption by renewable choline chloride-glycerol deep eutectic solvents. Green Chem 15(8):2261-2265

33. Zhang Q, De Oliveira VK, Royer S et al (2012) Deep eutectic solvents: syntheses, properties and applications. Chem Soc Rev 41(21):7108-7146

34. Jin M, Hou Y, Wu W et al (2011) Solubilities and thermodynamic properties of $\mathrm{SO}_{2}$ in ionic liquids. J Phys Chem B 115(20):6585-6591

35. Wishart JF (2009) Energy applications of ionic liquids. Energy Environ Sci 2(9):956-961

36. Gao X, Guo RT, Ding HL et al (2009) Dissolution rate of limestone for wet flue gas desulfurization in the presence of sulfite. $\mathrm{J}$ Hazard Mater 168(2-3):1059-1064

37. Ren SH, Hou YC, Tian SD et al (2012) Deactivation and regeneration of an ionic liquid during desulfurization of simulated flue gas. Ind Eng Chem Res 51(8):3425-3429

38. Rallo M, Lopez-Anton MA, Perry R et al (2010) Mercury speciation in gypsums produced from flue gas desulfurization by temperature programmed decomposition. Fuel 89(8):2157-2159

39. Huang $\mathrm{K}$, Chen YL, Zhang XM et al (2014) $\mathrm{SO}_{2}$ absorption in acid salt ionic liquids/sulfolane binary mixtures: experimental study and thermodynamic analysis. Chem Eng J 237:478-486 
40. National Institute of Standards and Technology. US Department of Commerce (2016) Thermophysical properties of fluid systems. http://webbook.nist.gov/chemistry/fluid/

41. Smith JM, Van Ness HC, Abbott MM (1996) Introduction to chemical engineering thermodynamics. McGraw-Hill, New York

42. Fang Y, Xue JX, Ke LY et al (2016) Polymeric lipid vesicles with $\mathrm{pH}$-responsive turning on-off membrane for programed delivery of insulin in GI tract. Drug Deliv 23(9):3582-3593

43. Nikouei NS, Ghasemi N, Lavasanifar A (2016) Temperature/pH responsive hydrogels based on poly(ethylene glycol) and functionalized poly(e-caprolactone) block copolymers for controlled delivery of macromolecules. Pharmaceut Res 33(2):358-366

44. Kestin J, Sokolov M, Wakeham WA (1978) Viscosity of liquid water in the range $-8^{\circ} \mathrm{C}$ to $150^{\circ} \mathrm{C}$. J Phys Chem Ref Data 7(3):941-948

45. Tian SD, Hou YC, Wu WZ et al (2014) Absorption of $\mathrm{SO}_{2}$ at high temperatures by ionic liquids and the absorption mechanism. Bull Korean Chem Soc 35(9):2791-2796
46. Pekel N, Guven O (2002) Synthesis and characterization of poly(N-vinyl imidazole) hydrogels crosslinked by gamma irradiation. Polym Int 51(12):1404-1410

47. Kuba AG, Smolin YY, Soroush M et al (2016) Synthesis and integration of poly(1-vinylimidazole) polymer electrolyte in dye sensitized solar cells by initiated chemical vapor deposition. Chem Eng Sci 154:136-142

48. Hong SY, Kim H, Kim YJ et al (2014) Nitrile-functionalized tertiary amines as highly efficient and reversible $\mathrm{SO}_{2}$ absorbents. $\mathrm{J}$ Hazard Mater 264:136-143

49. Tian S, Hou Y, Wu W et al (2014) Hydrophobic task-specific ionic liquids: synthesis, properties and application for the capture of $\mathrm{SO}_{2}$. J Hazard Mater 278:409-416 